\title{
Novel Interventional Techniques for Chronic Pain with Minimally Invasive Arthrodesis of the Sacroiliac Joint: (INSITE, iFuse, Tricor, Rialto, and others)
}

\author{
Alan D. Kaye $\cdot$ Amber N. Edinoff $\cdot$ Logan Scoon $\cdot$ Sean Youn \\ Kyle J. Farrell · Aaron J. Kaye · Rutvij J. Shah · Elyse M. Cornett • \\ Azem A. Chami · Bruce M. Dixon • Michael A. Alvarado • \\ Omar Viswanath · Ivan Urits · Aaron K. Calodney
}

Received: May 11, 2021 / Accepted: July 9, 2021 / Published online: July 30, 2021

(C) The Author(s) 2021

\section{ABSTRACT}

Acute and chronic pain are public health issues that clinicians have been battling for years. Opioid medications have been a treatment option for both chronic and acute pain; however, they can cause unwanted complications and are a major contributor to our present opioid epidemic. The sacroiliac (SI) joint is a common cause of both acute and chronic low back pain. It affects about $15-25 \%$ of patients with axial low back pain, and up to $40 \%$ of patients

A. D. Kaye $(\bowtie) \cdot$ R. J. Shah · E. M. Cornett .

A. A. Chami - B. M. Dixon - M. A. Alvarado

I. Urits · A. K. Calodney

Department of Anesthesiology, LSU Health

Shreveport, Shreveport, LA, USA

e-mail: alan.kaye@lsuhs.edu

\section{A. N. Edinoff}

Department of Psychiatry and Behavioral Medicine, LSU Health Shreveport, Shreveport, LA, USA

\section{Scoon}

Georgetown University School of Medicine,

Washington, DC, USA

S. Youn · O. Viswanath

University of Arizona College of Medicine-Phoenix, Phoenix, AZ, USA

K. J. Farrell · O. Viswanath

Department of Anesthesiology, Creighton

University School of Medicine, Omaha, NE, USA with ongoing pain following lumbar fusion. Recent advances in the treatment of SI joint pain have led to the development of a wide variety of SI joint fusion devices. These fusion devices seek to stabilize the joints themselves in order that they become immobile and, in theory, can no longer be a source for pain. This is a minimally invasive procedure aimed to address chronic pain without subjecting patients to lengthy surgery or medications, including opioids with the potential for addiction and abuse. Minimally invasive SI fusion can be performed by a lateral approach (i.e., iFuse, Tricor) or posterior approach (i.e., CornerLoc, LinQ,

\author{
A. J. Kaye \\ Department of Anesthesiology and Perioperative \\ Medicine, Medical University of South Carolina, \\ Charleston, SC, USA \\ O. Viswanath \\ Valley Anesthesiology and Pain \\ Consultants-Envision Physician Services, Phoenix, \\ AZ, USA \\ I. Urits \\ Southcoast Health, Southcoast Physicians Group \\ Pain Medicine, Wareham, MA, USA
}

A. K. Calodney

Precision Spine Care, Tyler, TX, USA

\section{A. D. Kaye}

Department of Academic Affairs, LSU Health

Shreveport, 1501 Kings Hwy, Shreveport, LA 71103,

USA 
Rialto). The posterior approach requires the patient to be in the prone position but allows for less disruption of muscles with entry. More data are necessary to determine which fusion system may be best for a particular patient. SI fusion devices are a promising way of treating chronic lower back pain related to the SI joint. This narrative review will discuss various types of SI fusion devices, and their potential use in terms of their safety and efficacy.

Keywords: SI Joint pain; Low back pain; CornerLoc; Rialto; iFuse; Tricor; Minimal invasive surgery

\section{Summary Points}

While opioid medications have been used to treat both chronic and acute pain, they can cause unwanted side effects and are a significant contributor to the current opioid epidemic.

The sacroiliac joint (SI) is a frequent source of low back pain, both acute and chronic. Recent advancements in the treatment of SI joint pain have resulted in the creation of a diverse range of SI joint fusion devices.

These fusion devices seek to immobilize the joints so that they can no longer be a source of pain. This is a minimally invasive procedure designed to alleviate chronic pain without requiring patients to undergo lengthy surgery or take medications, including opioids that carry the risk of addiction and abuse.

SI fusion can be performed minimally invasively via a lateral approach (i.e., iFuse, Tricor) or a posterior approach (i.e., CornerLoc, LinQ, Rialto).

Additional data are required to determine which fusion system may be the most appropriate for a particular patient. SI fusion devices offer hope for chronic lower back pain associated with the SI joint.

\section{INTRODUCTION}

Acute and chronic pain are public health issues that clinicians have been battling for years. Opioid medications have been the mainstay of treatment for both acute and chronic pain, but deaths from prescribed opioids have more than quadrupled in the USA since 1999, and the same pattern is now occurring all over the world [1]. Chronic pain, which occurs in about $10 \%$ of those who have surgery, typically begins as acute pain that is difficult to control but that can progress into and persist as a pain condition with neuropathic features unresponsive to opioids [1]. It is at this point that closer attention should be paid to the treatment of pain considered to be "difficult to control" to stop the progression to chronic pain. It has been proposed that a closer look at genetics and neurophysiological characteristics of patients might favor certain medications. As well, anatomic and metabolizing patterns of individual patients should be taken into consideration [2].

Sacroiliac joint (SI) pain is a common cause of both acute and chronic low back pain, affecting about $15-25 \%$ of patients with axial low back pain [3]. In the past, a common method to diagnose SI pain was the use of a small dose of local anesthetic [3]. SI joint pain must be distinguished from pain emanating from the lumbar spine, the SI joint itself, and the hip joint [4]. Cluneal nerve pathology and soft tissue pathology should also be considered in the differential diagnosis. Since pain in this region can stem from multiple causes, it is important for clinicians to take a thorough history to try to identify the source of the pain in the SI region and closely evaluate physical examination findings. The causes of and risk factors for SI joint pain are presented in Table 1.

Recent advances in the treatment of SI joint pain have led to the creation of SI joint fusion devices. These fusion devices seek to stabilize the joints themselves so that they are immobile and, in theory, can no longer be a source of pain. This is a minimally invasive procedure aimed to address the chronic pain endured by patients without subjecting them to lengthy surgery or medications with the potential for 
Table 1 Sacroiliac joint pain causes and risk factors

SI joint pain causes and risk factors

\begin{tabular}{|c|c|}
\hline Risk factor & Description \\
\hline Gait issues & $\begin{array}{l}\text { Leg length discrepancy or scoliosis can exert unequal pressure on one side of the pelvis, } \\
\text { resulting in wear and tear on the SI joint and an increased risk of discomfort }\end{array}$ \\
\hline Pregnancy or recent childbirth & $\begin{array}{l}\text { Sacroiliac joint discomfort is frequently experienced by women as a result of weight } \\
\text { gain, hormonal changes that lead ligaments in the SI joint to loosen (hypermobility), } \\
\text { and pelvic changes associated with delivery. Ligaments may remain loose in certain } \\
\text { women following delivery, resulting in continued SI joint discomfort and instability }\end{array}$ \\
\hline Prior lower back surgery & $\begin{array}{l}\text { SI discomfort can be more prevalent following fusion surgery than following } \\
\text { discectomy. Furthermore, multi-level surgery can be more likely than single-level } \\
\text { surgery to result in SI joint discomfort. SI joint discomfort has also been observed } \\
\text { following hip joint replacement surgery and iliac bone grafts (the pelvic "wings") }\end{array}$ \\
\hline $\begin{array}{l}\text { Activities that place repeated } \\
\text { stress on the joint }\end{array}$ & $\begin{array}{l}\text { Contact sports, regular heavy lifting, or labor-intensive work are all examples of labor- } \\
\text { intensive jobs. Stress from extended sitting or standing may also lead to SI joint } \\
\text { discomfort if pelvic and/or low back muscles are unconditioned }\end{array}$ \\
\hline Traumatic injury & $\begin{array}{l}\text { A abrupt impact, such as a collision with another car or a fall, can cause injury to SI } \\
\text { joints }\end{array}$ \\
\hline Arthritis & $\begin{array}{l}\text { SI joints can develop wear-and-tear arthritis (osteoarthritis), and ankylosing } \\
\text { spondylitis-a kind of inflammatory arthritis that affects the spine }\end{array}$ \\
\hline Infection & The SI joint can get infected in rare instances \\
\hline
\end{tabular}

This is an original table created by the authors with revised information [7]

SI Sacroiliac

addiction and abuse, such as opioids. In this article, therefore, our aim is to look at various types of SI fusion devices, and their potential use in terms of their safety and efficacy. It is important to note that these devices are not appropriate to treat SI joint pain due to spondyloarthritis, in which the "high" intensity activity is efficacious in the reduction of burden of the disease $[5,6]$.

This article is based on previously conducted studies and does not contain any new studies with human participants or animals performed by any of the authors.

\section{Posterior Versus Lateral Minimally Invasive SI Joint Fusion}

Lateral minimally invasive (MIS) SI joint fusion is performed using the transiliac approach with the placement of devices to transfix the SIJ to fuse the ilium and upperpart of the sacrum. This is accomplished using a lateral or posterolateral approach, with placement of the device through the ilium in the direction of the sacrum via SIJ. More than 20 devices are currently approved by the US Food and Drug Administration (FDA) for this procedure. The FDA indication statement illustrates their use in patients with chronic SI joint pain and/or traumatic or degenerative disruption.

In the posterior approach, the allograft bone products and/or devices are implanted into the ligamentous portion of the SIJ using a small incision to the skin and soft tissue and dissecting through muscle. A portion of the interosseous SI joint ligament is also typically removed. Most of the devices used for this procedure are unclassified allograft bone products originating from human cells and tissues, and thus the FDA 
does not provide any clear indication statement specific to SI joint fusion [24].

There are arguments and support from the supporters of both the approaches. The posterior MI-SIF joint fusion has the benefits of being less invasive, requiring less surgical dissection and surgical time, and having less bony destruction. The posterior approach can be done with intravenous sedation, and patients can walk out of the post-anesthesia care unit in $1 \mathrm{~h}$. The argument in favor of a lateral approach include a low revision rate, minimal complication rate, and a more stable fusion as posteriorly placed grafts may fail to fuse the joint effectively due to being in a ligamentous portion of the joint and possibly creating pseudarthrosis secondary to graft resorption or fracture [24]. The lateral transiliac approach yields radiographic evidence of bridging bone (fusion) across the articular portion of the SI joint in $85 \%$ of patients. [29] There is a data gap with robust literature supporting the use of a lateral approach and a smaller but growing body of evidence supporting the efficacy of posterior MI-SIF joint fusion.

In this paper, therefore, we describe several products using both the lateral and posterior approaches for MIS fusion.

\section{iFuse Implant}

The Investigation of Sacroiliac Fusion Treatment (INSITE) was a prospective, multicenter, open-label randomized controlled trial (RCT) that enrolled patients (ages $21-70$ years) with a diagnosis of unilateral or bilateral SI joint dysfunction related to degenerative sacroiliitis and/ or SI joint disruption between January 2013 and May 2019 at 19 institutions in the USA. It was the first randomized clinical trial to compare surgical and non-surgical management (NSM) of SI joint dysfunction. Surgical management consisted of minimally invasive SI joint fusion with the iFuse Implant System (SI-Bone, Santa Clara, CA, USA) involving triangular titanium implants (Fig. 1). NSM involved medication management, physical therapy per the American Physical Therapy guidelines for SI joint pain, intra-articular steroid injection, and radiofrequency ablation of the lateral branches of the sacral nerve roots. SI joint pain was measured with a 100-point Visual Analog Scale (VAS), disability was measured with the Oswestry Disability Index (ODI), and quality of life was measured by both the EQ-5D (a standardized measure of health-related quality of life developed by the EuroQol Group) and SF-36 (a 36-item health survey consisting of generic, coherent, and easily administered quality-of-life measures). The primary endpoint was a binary success/failure composite endpoint. At month six, 83 of 102 subjects in the SI joint fusion cohort met the primary endpoint, and the intent-to-treat difference in success rate was $54.5 \%$ [8]. Surgical treatment, when compared to NSM, was associated with improvements in pain, disability, and quality of life. More specifically, at 12 months: VAS pain improvement with surgical management was $81.6 \%$ versus $12.5 \%$ for NS, and ODI score improvement with surgical management was $72.4 \%$ versus $10 \%$ for NSM [8]. Patients were allowed to crossover from the NSM arm to the surgical management arm after the 6-month mark. Patients who crossed over had similar improvements in pain (mean decrease of 42.5 points; $P<0.001$ ) and ODI (mean decrease of 26.3 points; $P<0.001$ ) at the 6 -month followup [8].

Further analysis of the INSITE data in conjunction with the National Health Interview Survey (NHIS) was utilized to assess the effect of SI joint fusion and worker productivity. The NHIS is a source of information on the health of the civilian non-institutionalized population in the USA [9]. Regression analysis of NHIS data established a relationship between functional status and productivity, which was applied to health-related factors of patients who received
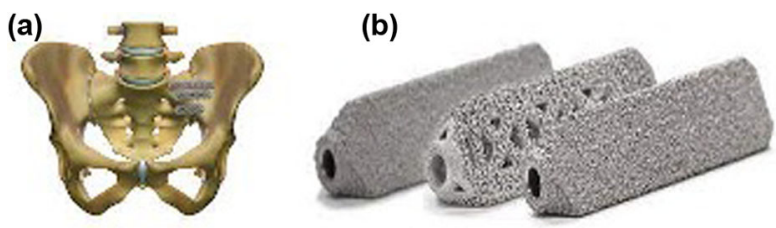

Fig. 1 a Three iFuse implants inserted in the sacroiliac (SI) joint using the lateral approach. b iFuse titanium porous implants. (Source: iFuse Implant System; SI-Bone, Santa Clara, CA, USA) 
surgical versus NSM of chronic SI joint dysfunction. This was then used to forecast productivity and earnings. Patients who received surgical management with SI joint fusion utilizing the iFuse Implant System were estimated to have an increased probability of working (approximately 16\%) and increased change in earnings (US\$3,128 per year) [10]. When combined together, this resulted in an estimated increase in productivity with a valuation of approximately US $\$ 6,900$ per year [10].

Pooled analysis of the INSITE trial along with the iFUSE Implant System Minimally Invasive Arthorodesis (iMIA) trial and Sacroiliac Joint Fusion with iFuse Implant System (SIFI) demonstrated improvement in pain, disability, and quality of life. These trials utilize a lateral to medial minimally invasive surgical approach. At 6 months, the adjusted reduction in SI joint pain was 37.9 points (95\% confidence interval [CI $32.5-43.4, P<0.0001)$ and the ODI was reduced by 18.3 points $(95 \%$ CI 14.3-22.4, $P<0.0001$ ) for surgical management versus NSM [11]. Importantly, there was reduced improvement for surgical management in those who smoked cigarettes, used opioids, were of lower age ( $<45$ years), and had shorter duration of SI joint pain [11]. Long-term outcomes from INSITE and SIFI (LOIS) included subjects from both the SIFI and INSITE studies with published results at 5 years. At 5 years, the ODI showed a mean improvement from baseline of 26 points, and the mean point improvement in pain from baseline was 54 points. Radiographic fusion was demonstrated in $85 \%$ of the subjects. [29].

\section{TriCor}

Minimally invasive sacroiliac fusion (MI-SIF) can be performed by a lateral approach (i.e., iFuse, Tricor) or posterior approach (i.e., CornerLoc). Current medical literature supports the use of the lateral approach with only a limited studies supporting the use of the posterior approach [6]. Lateral approaches are generally performed by surgeons, with $>80 \%$ of MI-SIF performed via this technique [6].

A lateral surgical approach is used to implant the TriCor Sacroiliac Joint Fusion System (Fig. 2) $[12,13]$. TriCor consists of three titanium- plated, cannulated, cylindrical screws that are designed to facilitate true bony fusion and arthrodesis across the sacroiliac joint [12]. Two of the cannulated screw implants are fenestrated to allow for allograft packing to promote arthrodesis that vary in volume from 1.5 to $3.5 \mathrm{cc}$ with length. These two anchor implants

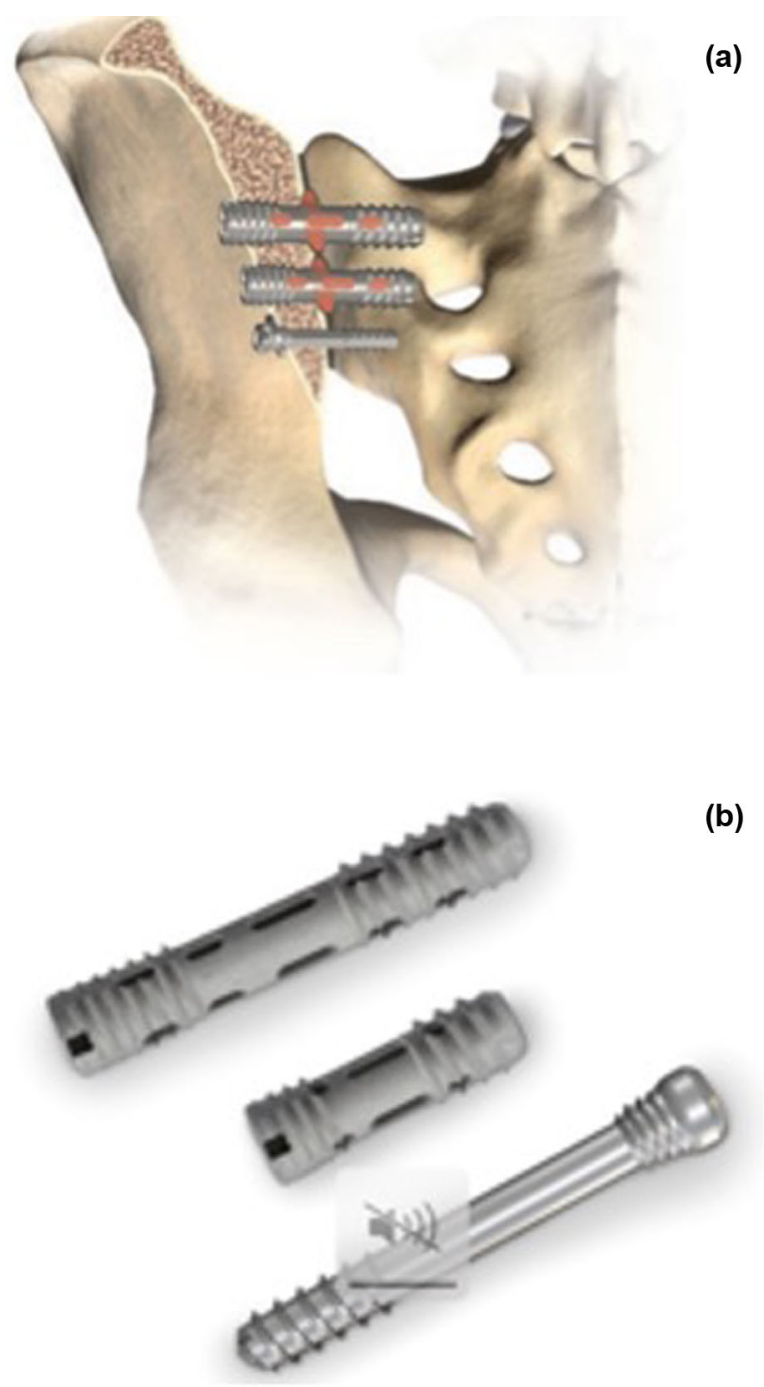

Fig. 2 a The TriCor Sacroiliac Joint Fusion System in place. b This system consists of 3 cylindrical, partially threaded, cannulated titanium-plated screw implants. The two superiorly placed screws are fenestrated to allow for bone graft filling to promote fusion. The most caudal screw serves as a locking implant with an optional 13.5$\mathrm{mm}$ washer that lies on the posterior surface of the pelvis. Surgical access for implantation is obtained via a lateral approach [2] 
have a diameter of $12.5 \mathrm{~mm}$ and vary in length from 30 to $70 \mathrm{~mm}$, determined by the surgeon to account for anatomical variation in patients. The third implant serves as a locking implant and has a 7-mm diameter with an optional 13.5$\mathrm{mm}$ washer that lies along the cortex of the pelvis to improve load bearing. Similarly, the screw lengths vary from 30 to $70 \mathrm{~mm}$. Kirschner wires are inserted first to confirm correct placement using inlet, outlet, and transiliac views on fluoroscopy. Then the appropriately sized cannulated, partially threaded, and cancellous sacroiliac screws described above are placed using the guidewires. TriCor was brought to market by Zimmer Biomet in 2014. As of February 2021, one published case-report referenced the use of TriCor [14]. The device was an obstacle in a subsequent spinopelvic fixation operation in a 71-year-old female with pre-existing sagittal imbalance, and the surgical technique was described.

\section{CornerLoc}

A posterior surgical approach is used to implant the CornerLoc Allograft-based Sacroiliac Stabilization System (Foundation Fusion Solutions, Tulsa, OK, USA; Fig. 3), which has been on the market since 2017. CornerLoc consists of two cortical allografts that are placed orthogonally to prevent migration and SIJ disruption [15]. CornerLoc does not contain any metal and does not require general anesthesia. The procedure is (a)

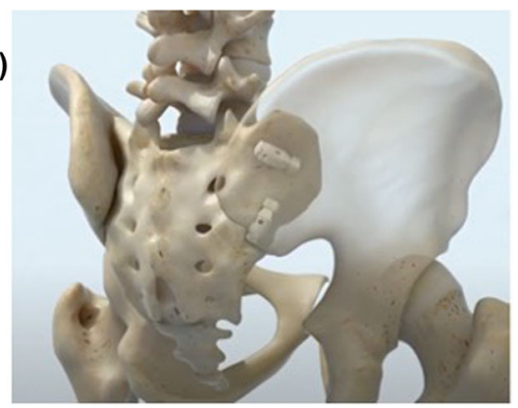

(b)

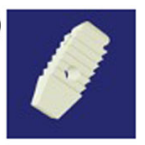

Fig. 3 a The CornerLoc ${ }^{\mathrm{TM}}$ Allograft-based SI Stabilization System in place. $\mathbf{b}$ This system consists of 2 biologic implants composed of demineralized bone matrix that are positioned orthogonally to prevent migration and improve the strength of fusion. Surgical access for implantation is obtained via a posterior approach [4] performed under intravenous sedation and local anesthesia and takes $<45 \mathrm{~min}$ to perform., which has been on the market since 2017 .

There appeared to be no published literature that evaluated or utilized CornerLoc prior to February 2021. However, a randomized, multicenter, open-label study is currently in the recruitment phase. The manufacturer of CornerLoc is sponsoring the study of 120 adult subjects to compare its device to intra-articular SI joint steroid injection. The primary endpoint will determine the efficacy and safety of CornerLoc compared to the standard of care at 6 months. The efficacy response rate will be defined as the percentage of patients who experience at least 50\% improvement in overall pain as measured by the Numeric Rating Scale for Pain. Study completion is aimed for September 2022. Table 2 presents a summary of novel devices available for minimally invasive SI arthrodesis.

\section{Rialto}

The Rialto SI Fusion System (Fig. 4) consists of a cylindrical threaded device that is designed to enhance SI joint fusion [16]. There are various different lengths that can accommodate differences in patients' anatomy. One to three of these devices may be placed at the clinician's discretion for joint stabilization [16]. There are some risks associated with the placement of this SI fusion device, which are the same as risks to any surgical procedure, such as the general risk of anesthesia, blood clots, and infection. Risks that are specific to SI fusion devices are incomplete pain relief, damage to the nerve roots, and complications with the hardware [16].

The Rialto SI Fusion System uses a posterior approach to the SI joint, where other fusion systems may use a lateral approach. This means that the patient will be placed in a prone position instead of a supine position [16]. The posterior placement may present an additional challenge to the anesthesiologis in terms of airway protection, which should be considered in the preoperative counseling of patients. The posterior approach does have advantages as it allows for minimal disruption of the muscles [16], which allows for this approach to be less invasive than others. 
Table 2 Table of novel devices available for minimally invasive sacroiliac arthrodesis

\begin{tabular}{|c|c|c|c|c|c|}
\hline $\begin{array}{l}\text { SI fusion } \\
\text { device }\end{array}$ & Description & $\begin{array}{l}\text { Number } \\
\text { of } \\
\text { implants }\end{array}$ & $\begin{array}{l}\text { Surgical } \\
\text { approach }\end{array}$ & Clinical studies & $\begin{array}{l}\text { Distributor } \\
\text { (year } \\
\text { available) }\end{array}$ \\
\hline iFuse & $\begin{array}{l}\text { Titanium construction, porous } \\
\text { surface allows bony growth/ } \\
\text { ingrowth }\end{array}$ & 3 & Lateral & $\begin{array}{l}\text { One post-marketing surveillance } \\
{[32] \text {, multiple clinical trials }} \\
{[33,34,35,36,37]}\end{array}$ & $\begin{array}{l}\text { SI-BONE } \\
(2009)\end{array}$ \\
\hline TriCor $^{\mathrm{TM}}$ & $\begin{array}{l}\text { Titanium alloy, screws } \\
\text { titanium-plated, cylindrical, } \\
\text { cannulated, partially } \\
\text { threaded }\end{array}$ & 3 & Lateral & None found Case report [3] & $\begin{array}{l}\text { Zimmer } \\
\text { Biomet } \\
\text { Spine, Inc } \\
(2014)\end{array}$ \\
\hline CornerLoc $^{\mathrm{TM}}$ & $\begin{array}{l}\text { Biologic, allograft } \\
\text { demineralized bone matrix, } \\
\text { rectangular cuboid-shaped, } \\
\text { cannulated, partially } \\
\text { threaded }\end{array}$ & 2 & Posterior & $\begin{array}{l}1 \text { open-label }(n=120) \text { to be } \\
\text { compete Sept } 2022[5]\end{array}$ & $\begin{array}{l}\text { Foundation } \\
\text { Fusion } \\
\text { Solutions } \\
(2017)\end{array}$ \\
\hline Rialto $^{\mathrm{TM}}$ & $\begin{array}{l}\text { Cylindrical threaded devices, } \\
\text { Bone graft can be delivered } \\
\text { within the device }\end{array}$ & $1-3$ & Posterior & One retrospective case series [19] & $\begin{array}{l}\text { Medtronic } \\
(2016)\end{array}$ \\
\hline $\begin{array}{l}\text { PainTEQ } \\
\text { LinQ } \\
\text { device }\end{array}$ & Biologic allograft implant & 1 & Posterior & $\begin{array}{l}\text { No RCT available. A Single Arm, } \\
\text { Multicenter, Prospective, } \\
\text { Clinical Study is currently } \\
\text { underway. Expected study } \\
\text { completion date } 03 / 21 / 2022 \\
\text { [38] }\end{array}$ & $\begin{array}{l}\text { PainTEQ } \\
\quad(2020)\end{array}$ \\
\hline
\end{tabular}

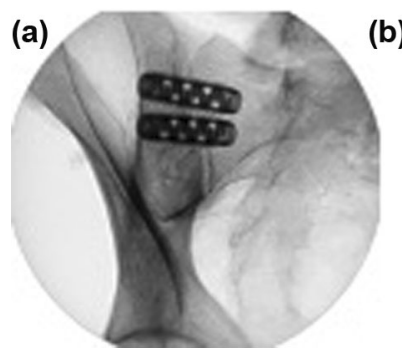

(b)

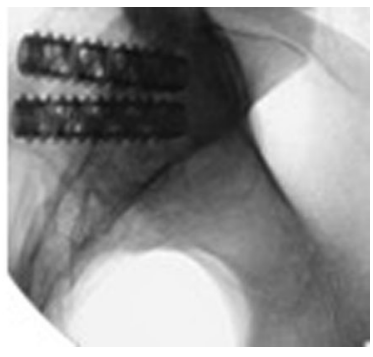

Fig. 4 a, b Rialto ${ }^{\mathrm{TM}}$ anteroposterior (a) and lateral fluoroscopic (b) views of Medtronic Rialto cylindrical implants. (Source: Medtronic plc; Dublin, Ireland)

The Rialto system is contraindicated for patients with deformities, tumor resection, infection to the local operative site, or suspected or documented allergy to the component materials [17]. Potential warnings should be given to the patient in the pre-operative counseling sessions. Women of childbearing age should be cautioned that vaginal delivery may not be advisable following SI joint fusion [17]. It should also be noted that patients who have had prior surgery in the area may have different clinical outcomes than patients who have not had prior surgery in this area.

\section{PainTEQ}

Recently emerging surgical techniques for minimally invasive stabilization of the sacroiliac joint involve the posterior and posterioroblique approach. LinQ is a sacroiliac joint fusion system pioneered by PainTEQ (Tampa, FL, USA; Fig. 5), which utilizes a minimally 
invasive posterior percutaneous approach. The procedure involves initial decortication of the joint followed by insertion of the LinQ allograft spacer complete with demineralized bone matrix [18].

In a retrospective case series of 16 patients with chronic SI joint dysfunction who received the LinQ SI joint fusion system, improved pain and decreased opioid consumption were reported [19]. A multicenter prospective study of the LinQ system, SECURE (Single-arm, Multicenter, Prospective, Clinical Study on a Novel Minimally Invasive Posterior SI Fusion Device), is currently enrolling patients, 100 patients across nine centers, with the aim to investigate pain, adverse events, neurological progression, and the need for re-intervention.

\section{Clinical Studies: Safety and Efficacy}

\section{Rialto}

A retrospective chart review was performed, which looked at patients who had received the Rialto system and evaluated changes in low back pain and narcotic medication use [20]. This study was small and only included 14 patients from a single surgeon's private practice. The study did find that the patient's VAS scores had significantly decreased post-surgery, from a mean of 8.50 pre-surgery (judged to be baseline) to a mean of 3.21 at 12 months post-surgery (95\% CI 7.87-9.13 and 1.40-5.03 respectively; $p<0.0001)$. The morphine milligram equivalent (MME) was measured pre-surgery and at 1 and 12 months post-surgery. The mean MME (a)

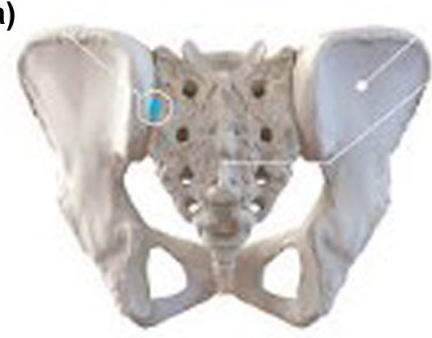

(b)

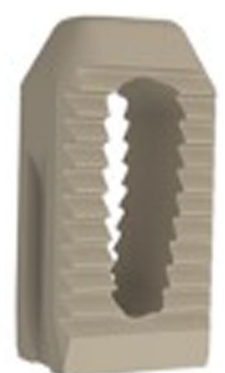

Fig. 5 a PainTeq Lin $Q^{\mathrm{TM}}$ device in place. $\mathbf{b}$ This device is implanted by a minimally invasive technique. Implant contains a window in the center which is filled with the bone allograft. (Source: PainTEQ; Tampa, FL, USA) was 25.00 pre-surgery, decreasing to 10.36 at 12 months post-surgery. The mean decrease in MME at baseline at the 1 month follow-up was 8.21 (95\% CI 3.74-12.69; $p=0.0016$ ) to 6.43 between 1 and 12 months (95\% CI 0.72-12.14; $p=0.0302)$, and the baseline at 12 months was 14.64 (95\% CI 7.90-21.39; $p=0.0004$ ) [20]. These results are promising. However, further studies need to be performed to see if these results can be replicated since the sample size was small and only from one private practice.

\section{Differences Between Systems}

A retrospective review of patients was performed to compare the clinical outcomes of SI joint fusion between cylindrical threaded implants (CTIs; Rialto, Medtronic) and triangular titanium implants (TTIs; iFUSE, SIBone) [21]. The outcomes reviewed were patient-reported ones, such as VAS scores and the ODI at 6 months and 1 year. In the review, 156 patients underwent SI joint fusions, 74 patients had CTIs, and 82 had TTIs. There was a significant difference in procedure length with CTI averaging averaged $60 \mathrm{~min}$ (95\% CI 55.7-64.3) and TDI averaging $41.2 \mathrm{~min}$ (95\% CI 38.4-43.9; $p<0.0005)$. There was a significant improvement in VAS scores and ODI at 6 months when compared to their pre-operative values. However, there was no significant difference after 6 months and at the 1 year follow-up between the two systems. The authors concluded that there was a significant improvement in pain and disability, but there was not a significant difference between the two systems [21].

Another retrospective chart review was performed that looked at outcomes with the Rialto system when using intraoperative stereotactic navigation [22]. Twenty-four patients were reviewed who underwent SI joint fusions between May 2015 and October 2017, all performed by a single surgeon. Mean satisfaction scores with the procedure were $89.0 \pm 27.6 \%$. The authors noted a statistically significant reduction in lower back pain scores from baseline $(3.7 \pm 3.3$ vs. $6.6 \pm 2.4$ [baseline]; $p=$ $0.0028)$ [22]. Leg pain scores decreased from $4.8 \pm 3.8$ to $1.5 \pm 2.9$ post-surgery $(p=0.0024)$ [22]. Surgical times using navigation were increased in the first 13 cases $(59.9 \pm 15.2 \mathrm{~min})$ 
compared to the subsequent cases $(45.4 \pm 7.3 \mathrm{~min})$ [22]. The authors concluded that the use of the Rialto system can be performed with good clinical outcomes.

\section{SI Fusion Devices in General}

A RCT was performed to assess the outcomes of surgical and non-surgical treatments for SI joint pain. A total of 148 subjects were randomly assigned to receive SI joint fusion with triangular titanium implants or NSM [23]. Pain, disability, and quality of life scores were collected at baseline and then at 1, 3, 6, and 12 months post-treatment. The 6-month success rates were higher in the surgical group (81.4 vs. $26.1 \%$ ) [23]. At 12 months, improvements in pain and disability were sustained in the surgical group. It should be noted that adverse events were more common in the surgical group but did not approach significance. The authors concluded that surgical treatment with the triangular titanium implants was more effective than NSM.

Another RCT also looked at surgical management with triangular titanium implants compared to conservative management (CM) [24]. The authors also looked at a separate analysis of the data to assess whether the referred leg pain (RLP) component of the SI joint pain may also be affected by surgical management versus CM. A total of 101 subjects were recruited between June 2013 and May 2015 at nine European spine centers, of whom 49 patients were randomized to receive $\mathrm{CM}$ and 51 were to receive surgical management. RLP was defined as pain below the gluteal fold and assessed using VAS scores. Changes in RLP over 6 months were the primary endpoints. Over 6 months, CM produced no significant change in RLP; in contrast, the surgical management group had a significant decrease in RLP from VAS at baseline (13.5 vs. 58.0; $p<0.01)$ [24].

Another RCT also looked at surgical and non-surgical treatment for SI joint pain [25]. In that study, 148 patients were randomly assigned to either minimally invasive SI joint fusion with triangular titanium implants or NSM. SI joint pain was measured using VAS scores, disability with ODI, and quality of life scores were also collected at baseline and at scheduled visits up to 24 months. By 24 months, the surgical group showed a decrease in pain, with a mean improvement in VAS score of 55.4 points. The mean change in VAS scores at 6 months was 12.2 points in the NSM group and 38.3 points in the surgical group $(p<0.0001)$. In terms of disability, 68.2 showed clinical improvement of $>15$ points and $65 . \%$ showed clinical improvement of $>18$ points in ODI scores at 24 months [25]. Adverse events were low in the surgical group, with only three patients undergoing revision surgery within the 24 months of follow-up [25]. The authors concluded that surgical management with the triangular titanium implants provided a larger improvement in pain, disability, and quality of life compared to NSM and that these improvements persisted to 24 months [25].

A 2-year multicenter prospective study looked at the results of surgical management 2 years after implantation of triangular titanium implants. In total, 172 subjects at 26 sites in the USA were enrolled and underwent minimally invasive SI joint fusion with the triangular titanium implants [26]. The subjects underwent structured assessments pre-operatively and at 1 , $3,6,12,18$, and 24 months post-operatively, and VAS, ODI, SF-36, EQ-5D, and patient satisfaction scores were recorded. All patients also underwent a high-resolution pelvic computed tomography (CT) scan at 1 year. VAS scores at baseline were 79.8 and decreased to 30.2 at 12 months, remaining at 26.0 at 24 months $(p<0.0001)$ [26]. ODI, the measure of disability, decreased from 55.2 at baseline to 31.5 at 12 months and 30.9 at 24 months $(p<0.001)$ [26]. Quality of life scores measured by the EQ5D showed improvements at both 12 and 24 months. The percentage of patients in the study who were taking opioids decreased from $76.2 \%$ to $55.0 \%$ at 24 months ( $p<0.001$ ). Only eight subjects at the time of the article's writing had undergone one or more revision surgeries. CT scans at 1 year showed a high rate of bone adherence to at least 2 implants (97\%) [26].

\section{CONCLUSION}

The SI joint is a common cause of both acute and chronic low back pain [3]. It affects about 
$15-25 \%$ of patients with axial low back pain $[25,26]$, and up to $40 \%$ of patients with ongoing pain following lumbar fusion. [27, 28].

In the past, SI joint pain was treated with injections of local anesthetics and corticosteroids, physical therapy, and opioid medications. Minimal invasive procedures have been developed to address chronic pain without subjecting patients to lengthy surgeries or longterm use of medications.

SI fusion devices were developed to stabilize the SI joint to minimize pain and improve function and quality of life for patients with SI joint pathology. A wide variety of devices have been developed and marketed. Posterior minimally invasive SI joint fusion relies on distraction as a strategy to achieve fusion, with tightening and tensioning lax ligaments to stabilize the joint. The lateral approach to minimally invasive SI joint fusion transfixes the joint to provide stability with well-studied biomechanics [30,31]. Although there is a more robust data set supporting the use of lateral transiliac minimally invasive SI joint fusion, the posterior approach has many potential advantages, and the number of supportive studies is growing [39, 40 and 41].

More data need to be obtained in terms of which fusion system may be better than another when compared head-to-head. In theory, a posterior approach appears to be less invasive and more readily adopted by spine interventionalists. No studies to the writers' knowledge have been done to look at the difference between the two approaches. SI fusion devices do pose a promising way of treating chronic lower back pain.

\section{ACKNOWLEDGEMENTS}

Funding. The authors declare no funding.

Disclosures. Alan D Kaye, Amber N Edinoff, Logan Scoon, Sean Youn, Kyle J Farrell, Aaron J Kaye, Rutvij J Shah, Elyse M Cornett, Azem A Chami, Bruce M Dixon, Michael A Alvarado, Omar Viswanath, Ivan Urits, and Aaron K. Calodney have nothing declare.
Authorship. All named authors meet the International Committee of Medical Journal Editors (ICMJE) criteria for authorship for this article, take responsibility for the integrity of the work as a whole, and have given their approval for this version to be published.

Author Contributions. Study concept and design: ADK, ANE, LS, SY, KJF, AJK. Analysis and interpretation of data: RJS, EMC, AAC, BMD, MAA. Drafting of the manuscript: ADK, ANE, LS, SY, KJF, AJK, RJS, EMC, AAC, BMD, MAA, $\mathrm{OV}, \mathrm{IU}, \mathrm{AKC}$. Critical revision of the manuscript for important intellectual content: ADK, ANE, LS, SY, KJF, AJK, RJS, EMC, AAC, BMD, MAA, OV, IU, AKC Statistical analysis: MAA, OV, IU, AKC.

Compliance with Ethic Guidelines. This article is based on previously conducted studies and does not contain any new studies with human participants or animals performed by any of the authors.

Data Availability. Data sharing is not applicable to this article as no datasets were generated or analyzed during the current study.

Open Access. This article is licensed under a Creative Commons Attribution-NonCommercial 4.0 International License, which permits any non-commercial use, sharing, adaptation, distribution and reproduction in any medium or format, as long as you give appropriate credit to the original author(s) and the source, provide a link to the Creative Commons licence, and indicate if changes were made. The images or other third party material in this article are included in the article's Creative Commons licence, unless indicated otherwise in a credit line to the material. If material is not included in the article's Creative Commons licence and your intended use is not permitted by statutory regulation or exceeds the permitted use, you will need to obtain permission directly from the copyright holder. To view a copy of this licence, visit http://creativecommons.org/licenses/bync/4.0/. 


\section{REFERENCES}

1. Glare P, Aubrey KR, Myles PS. Transition from acute to chronic pain after surgery. Lancet. 2019;393(10180):1537-46.

2. Allegri M, Clark MR, De Andrés J, Jensen TS. Acute and chronic pain: where we are and where we have to go. Minerva Anestesiol. 2012;78(2):222-35.

3. Cohen SP. Sacroiliac joint pain: a comprehensive review of anatomy, diagnosis, and treatment. Anesth Analg. 2005;101(5):1440-53.

4. DePhillipo NN, Corenman DS, Strauch EL, Zalepa King LA. Sacroiliac pain: structural causes of pain referring to the SI joint region. Clin Spine Surg. 2019;32(6):E282-8.

5. Reveille JD, Arnett FC. Spondyloarthritis: update on pathogenesis and management. Am J Med. 2005;118(6):592-603.

6. Perrotta FM, Lories R, Lubrano E. To move or not to move: the paradoxical effect of physical exercise in axial spondyloarthritis. RMD Open. 2021;7(1): e001480.

7. Dydyk AM, Forro SD, Hanna A. Sacroiliac ioint injury. In: StatPearls. Treasure Island: StatPearls Publishing; 2021. http://www.ncbi.nlm.nih.gov/ books/NBK557881/. Accessed 29 Jun 2021

8. INSITE Study Group, Polly DW, Cher DJ, et al. Randomized controlled trial of minimally invasive sacroiliac joint fusion using triangular titanium implants vs nonsurgical management for sacroiliac joint dysfunction. Neurosurgery. 2015;77(5): 674-91.

9. Adams PF, Kirzinger WK, Martinez M. Summary health statistics for the U.S. population: National Health Interview Survey, 2012. Vital Health Stat 2013;10(259):1-95.

10. Saavoss J, Koenig L, Cher D. Productivity benefits of minimally invasive surgery in patients with chronic sacroiliac joint dysfunction. Clin Outcomes Res. 2016;8:77-85.

11. Dengler J, Duhon B, Whang P, et al. Predictors of outcome in conservative and minimally invasive surgical management of pain originating from the sacroiliac joint: a pooled analysis. Spine. 2017;42(21):1664-73.

12. 360 Market Updates. Global MIS sacroiliac joint fusion market. https://www.360marketupdates. com/global-mis-sacroiliac-joint-fusion-market13716161. Accessed 28 Mar 2021.
13. Thoracolumbar Solutions. TriCor ${ }^{\mathrm{TM}}$ Sacroiliac Joint Fusion System - Surgical Technique Guide. p 32. https://www.zimmerbiomet.com/content/dam/ zimmer-biomet/medical-professionals/000-surgicaltechniques/spine/tri-cor-sacroiliac-joint-fusionsystem-surgical-technique-guide.pdf.

14. Laratta JL, Lin JD, Shillingford JN, Hardy NE, Reddy $\mathrm{H}$, Lehman RA. Obstructed spinopelvic fixation in the setting of a triangular titanium sacroiliac fusion implant: a case description. J Spine Surg. 2017;3(4): 732-5. $\quad$ https://doi.org/10.21037/jss.2017.11.11. PMID: 29354757; PMCID: PMC5760409.

15. For Physicians [Internet]. CornerLoc. [cited 2021 Mar 28]. Available from: https://cornerloc.com/forsi-joint-physicians/

16. Medtronic. SI joint fusion-sacroiliac joint fusion. https://www.medtronic.com/us-en/patients/ treatments-therapies/sacroiliac-joint-fusion/ treatment-options/si-fusion.html. Accessed 28 Mar 2021.

17. Medtronic. Important safety information-Rialto SI Fusion System. https://www.medtronic.com/us-en/ patients/treatments-therapies/sacroiliac-jointfusion/important-safety-information.html. Accessed 28 Mar 2021.

18. Suhy A. Prospective study announced for sacroiliac joint fusion device. This Week Orthopedics. 2020. https://ryortho.com/breaking/prospective-studyannounced-for-sacroiliac-joint-fusion-device/. Accessed 7 Mar 2021.

19. Kim D, Sayed D, Lamb C, Kim B, Oritz A, Pyles S. Initial experience with a minimally invasive sacroiliac fusion device, a retrospective case series. PainTEQ. 2020. https://painteq.com/doctors/news/ 2020/07/initial-experience-with-a-minimallyinvasive-sacroiliac-fusion-device-a-retrospectivecase-series/. Accessed 7 Mar 2021.

20. Cohen M. Minimally invasive sacroiliac joint fusion with Rialto SI Fusion System. Medtronic. 2016. https://www.globalcastmd.com/files/download/ 00e5f140a111066.

21. Claus CF, Lytle E, Kaufmann A, et al. Minimally invasive sacroiliac joint fusion using triangular titanium versus cylindrical threaded implants: a comparison of patient-reported outcomes. World Neurosurg. 2020;133:e745-50.

22. Rajpal S, Burneikiene S. Minimally invasive sacroiliac joint fusion with cylindrical threaded implants using intraoperative stereotactic navigation. World Neurosurg. 2019;122:e1588-91.

23. Polly DW, Cher DJ, Wine KD, et al. Randomized controlled trial of minimally invasive sacroiliac 
joint fusion using triangular titanium implants vs nonsurgical management for sacroiliac joint dysfunction: 12-month outcomes. Neurosurgery. 2015;77(5):674-90.

24. Dengler J, Sturesson B, Kools D, et al. Referred leg pain originating from the sacroiliac joint: 6-month outcomes from the prospective randomized controlled iMIA trial. Acta Neurochir (Wien). 2016;158(11):2219-24.

25. SI-BONE. INSITE 2-year results (Polly-IJSS). 2016. https://si-bone.com/providers/clinical-evidence/ data/two-year-outcomes-from-a-randomizedcontrolled-trial-of-minimally-invasive. Accessed 28 Mar 2021.

26. Duhon BS, Bitan F, Lockstadt H, Kovalsky D, Cher D, Hillen T. Triangular titanium implants for minimally invasive sacroiliac joint fusion: 2-year follow-up from a prospective multicenter trial. Int J Spine Surg. 2016. https://www.ncbi.nlm.nih.gov/ pmc/articles/PMC4852595/. Accessed 28 Mar 2021.

27. Lorio M, Kube R, Araghi A. International Society for the Advancement of Spine Surgery. Policy 2020 update-minimally invasive surgical sacroiliac joint fusion (for chronic sacroiliac joint pain): coverage indications, limitations, and medical necessity. Int J Spine Surg. 2020;14(6):860-95

28. Schwarzer AC, Aprill CN, Bogduk N. The sacroiliac joint in chronic low back pain. Spine. 1995;20(1): 31-7.

29. Depalma MJ, Ketchum JM, Saulloet T. What is the source of chronic low back pain and does age play a role? Pain Med. 2011;12(2):224-33.

30. Maigne JY, Planchon CA. Sacroiliac joint pain after lumbar fusion. A study with anesthetic blocks. Eur Spine J. 2005;14(7):654-8.

31. DePalma MJ, Ketchum JM, Saullo TR. Etiology of chronic low back pain in patients having undergone lumbar fusion. Pain Med. 2011;12(5):732-9.

32. Whang PG, Darr E, Meyer SC, et al. Long-term prospective clinical and radiographic outcomes after minimally invasive lateral transiliac sacroiliac joint fusion using triangular titanium implants. Med Devices (Auckl). 2019;12:411-22.
33. Casaroli G, Bassani T, Brayda-Bruno M, Luca A, Galbusera F. What do we know about the biomechanics of the sacroiliac joint and of sacropelvic fixation? A literature review. Med Eng Phys. 2019;76:1-12.

34. Shih YC, Beaubien BP, Chen Q, Sembrano JN. Biomechanical evaluation of sacroiliac joint fixation with decortication. Spine J. 2018;18(7):1241-9.

35. Miller LE, Reckling WC, Block JE. Analysis of postmarket complaints database for the iFuse SI Joint Fusion System ${ }^{\circledR}$ : a minimally invasive treatment for degenerative sacroiliitis and sacroiliac joint disruption. Med Devices (Auckl): 2013;6:77-84.

36. Cher D, Reckling W, Capobianco R. Implant survivorship analysis after minimally invasive sacroiliac joint fusion using the iFuse Implant System ${ }^{\circledR}$. Med Devices (Auckl). 2015;8:485-92.

37. Dale M, Evans J, Carter K, O'Connell S, Morgan H, Carolan-Rees G. iFuse implant system for treating chronic sacroiliac joint pain: a NICE medical technology guidance. Appl Health Econ Health Policy. 2019;18(3):363-73.

38. Scheyerer M, Hüllner M, Pietsch C, Veit-Haibach P, Werner C. Implant-bone interface of aacroiliac joint fusion using iFuse Implant System. ISRN Minimally Invasive Surg. 2014;2014:1-6.

39. Bornemann R, Roessler P, Strauss A, et al. Two-year clinical results of patients with sacroiliac joint syndrome treated by arthrodesis using a triangular implant system. Technol Health Care. 2017;25(2): 319-25.

40. Bornemann R, Pflugmacher R, Webler M, et al. Klinische Studie zur Prüfung des iFuse Implant Systems ${ }^{\circledR}$ bei Patienten mit Iliosakralgelenksyndrom: 1-Jahres-Ergebnisse [Clinical Trial to Test the iFuse Implant System ${ }^{\circledR}$ in Patients with Sacroiliac Joint Syndrome: One Year Results]. Z Orthop Unfall. 2016;154(6):601-5. https://doi.org/10.1055/ s-0042-110207.

41. Clinicaltrials.gov. Clinical study on a novel minimally invasive posterior sacroiliac fusion device. 2021. https://clinicaltrials.gov/ct2/show/NCT044 23120. Accessed 6 Apr 2021. 